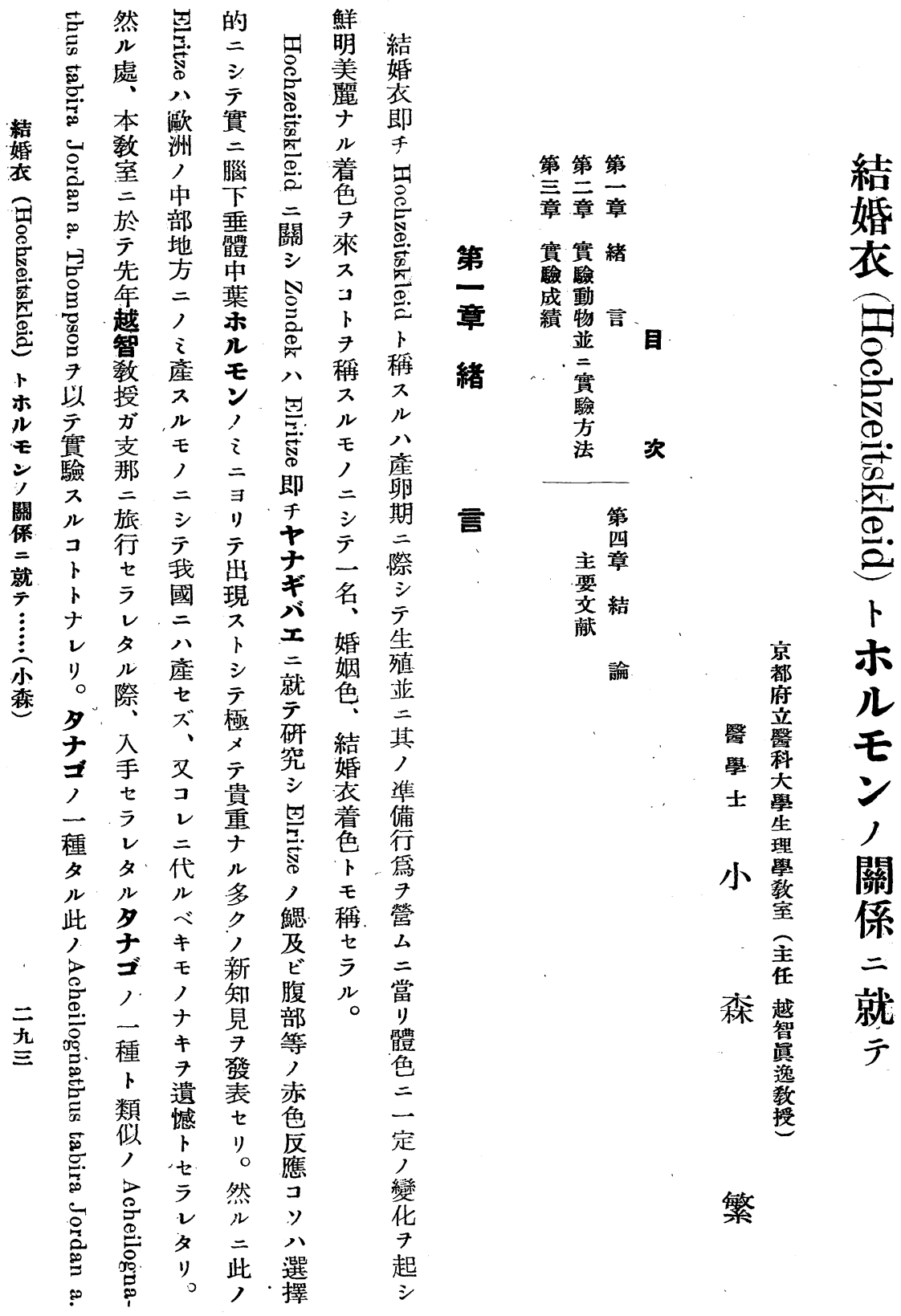




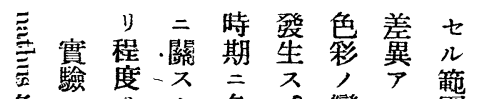
各紫差砛少。變少園

尾学究尖总华即於

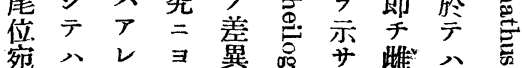

選五色 綵 黑

テ○細色魚 分之虚西品

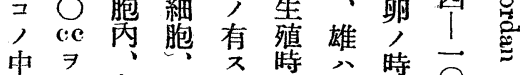

入入色赤膘期 䧳期

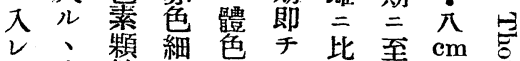

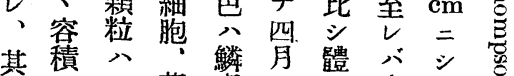

;

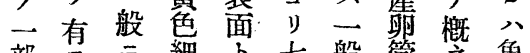

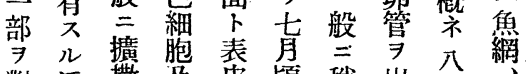

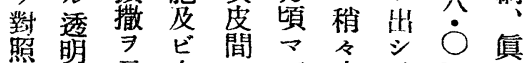

照确示白, デ大

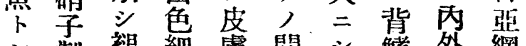

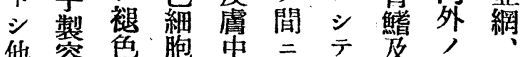

他突色胞中於全范モ條

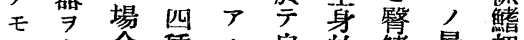

多合種儿鼻的躃最超

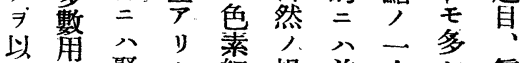

意聚上細場前小新。窄

實意團云胞合速部。㐫

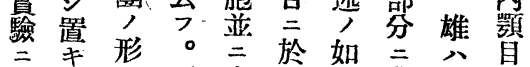

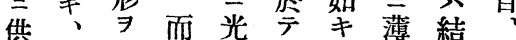

苂略

注同。出胞媤顯着着三

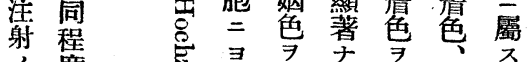

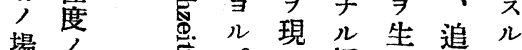

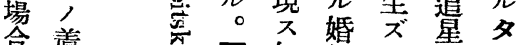

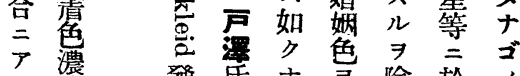

リ度登氏氐ナ寻除於,

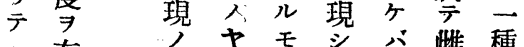

八有場り 個頭全会雌

芯次合乡體端全比シ

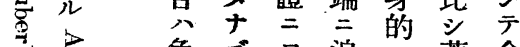

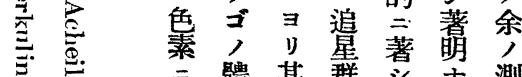

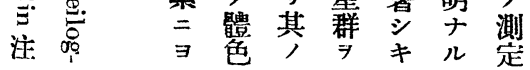

年亲色 鯥 共

容都彩亚 二 总

二近包壂少品

探二マ鯺濃ノ結

捕テ须厚芦衣

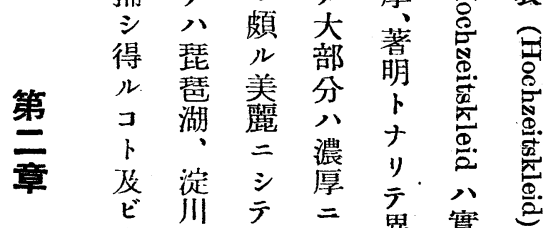

菑 多及恰 シ 䔬實

驗數 ビ モ テ常著

動 捕禁美新擴音

物 得等方䑩張 こ

並ル $ル$ 結ル シ ジ,

二 コ モ 婚 燃 タ 全關

惯 驗 等 多䘚 工

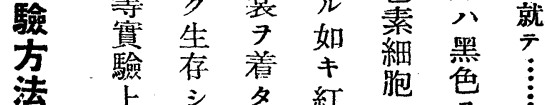

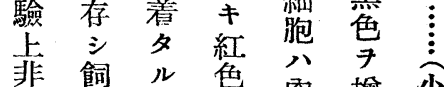

常養, 7 肉增一森

二簡 感 現 腮 背 㷊

好單、ア シ 都、学

合强 0 體 サ

ナ健此分黑 各

鮘年 小 二

テ、我部點 於

抵國稍卢甚

抗二々 シ ダ

力於青容 ま

强 少色易 、云

ナ廣帶二體四

ルクビ認ノ

, 分德 戸 腹

布 二 側

ナ シ 全 ル下

ラ居身 更 部

ズレ心更二

殆 ル 異 鰓 腹

- 如ナ部鰭 


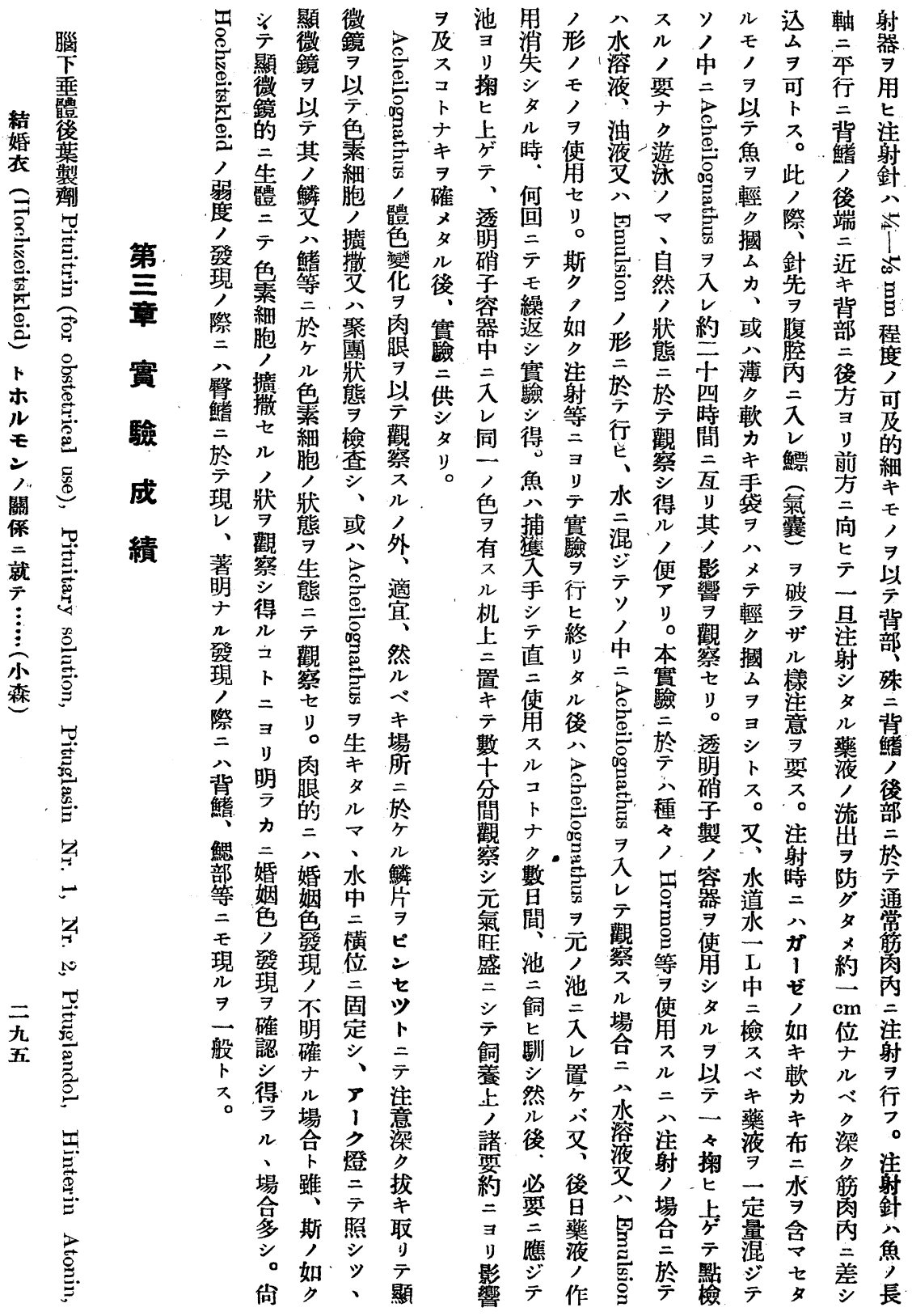




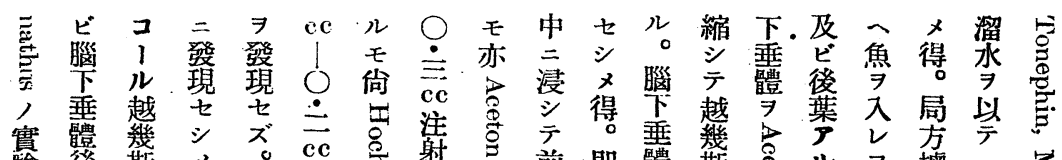

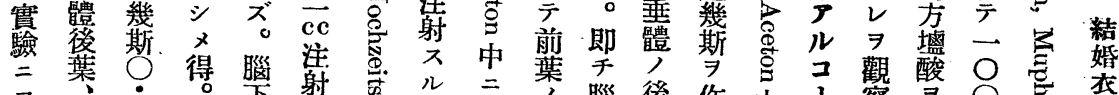

三 某

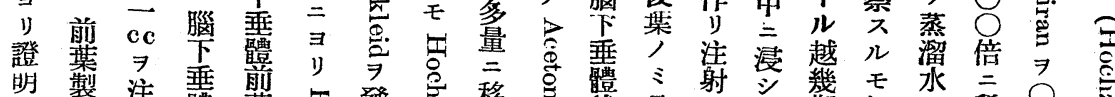

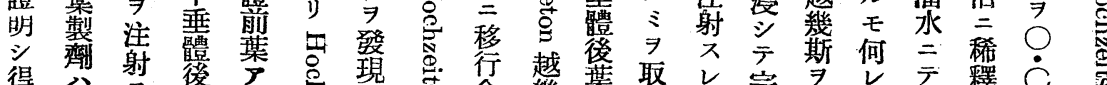

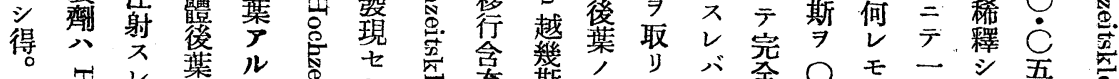

又心壳

紫 惫

線

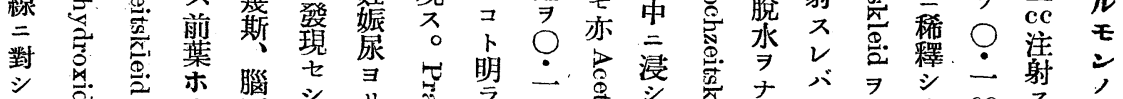
シ

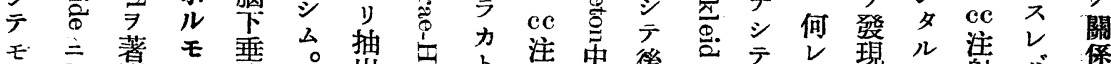

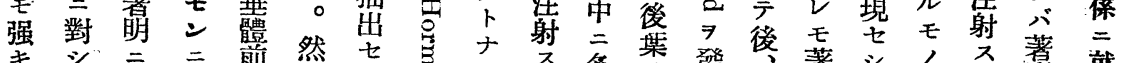
抵 $゙$ 發此䇎

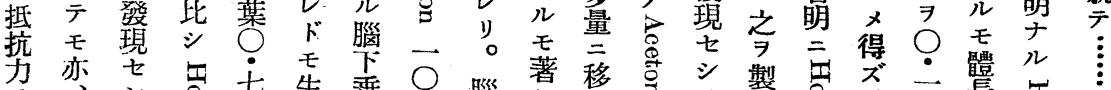
有

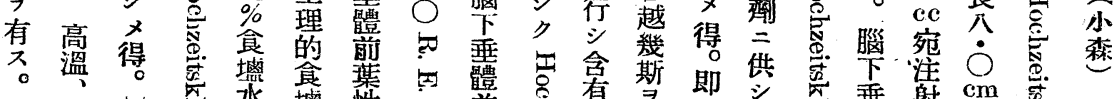

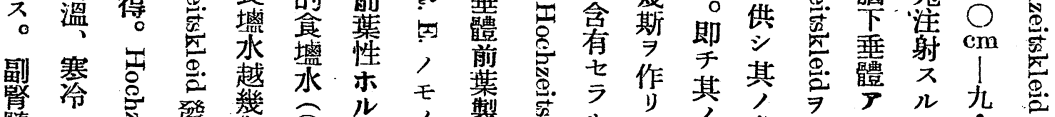

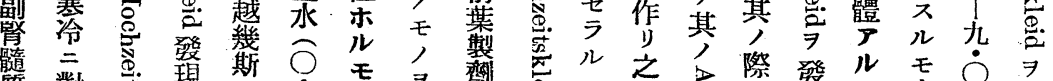
質 對 蛋 現斯?

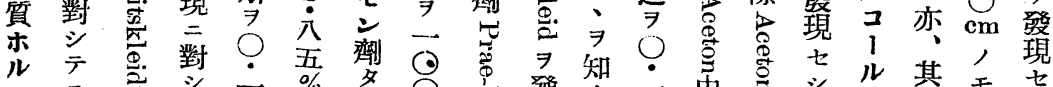
モ七 發

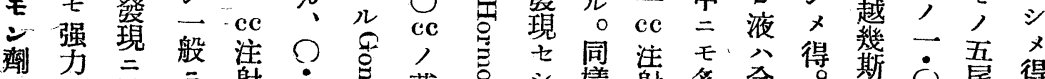

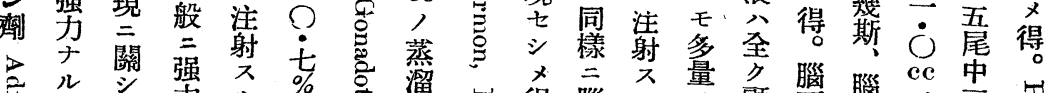

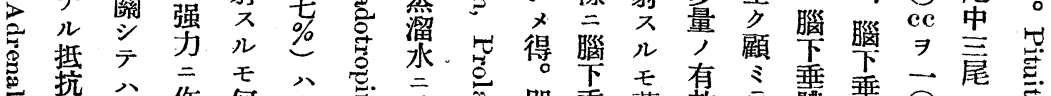

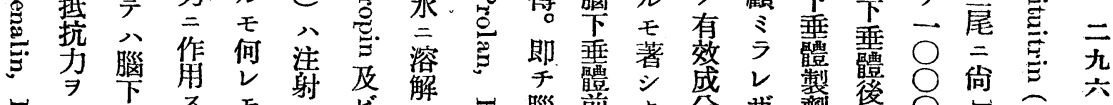

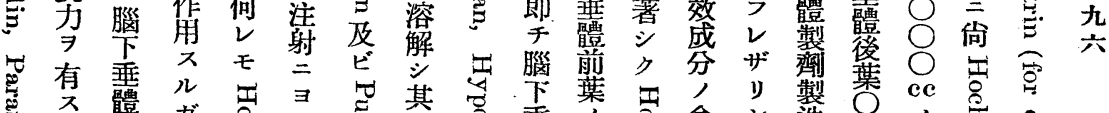
不體ガ

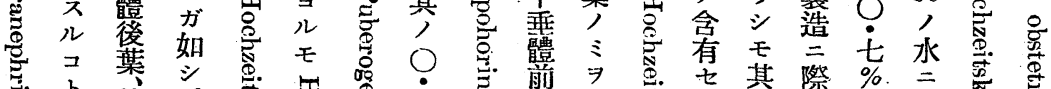
志

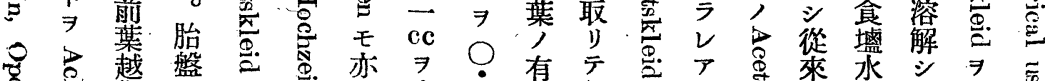

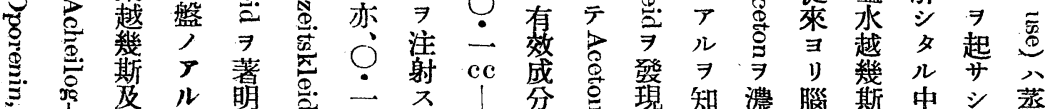

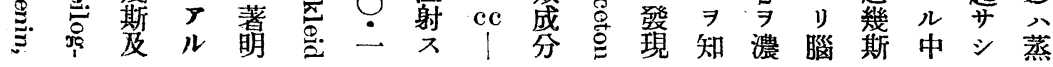




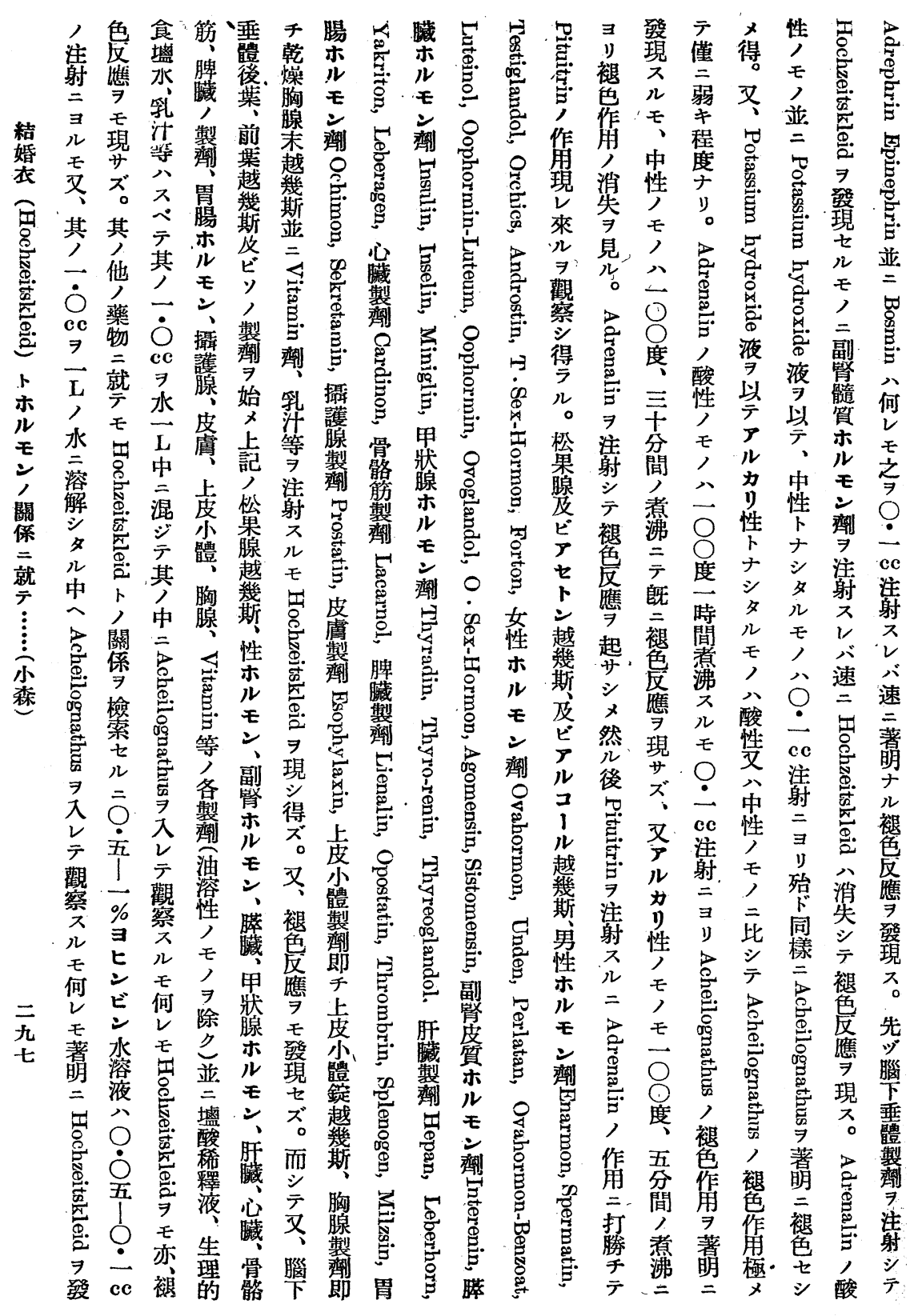




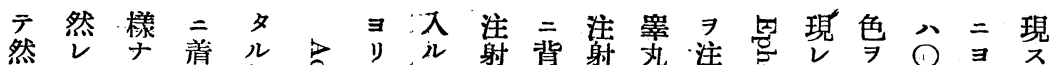
後 白毄夺機部怘分芭

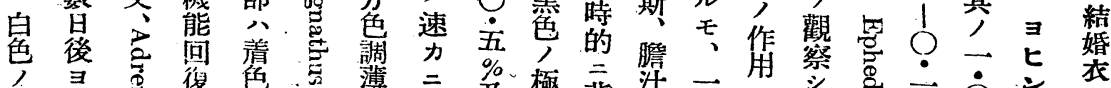

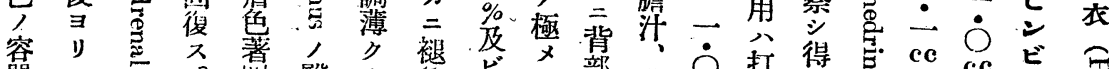

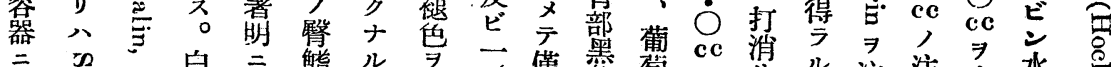

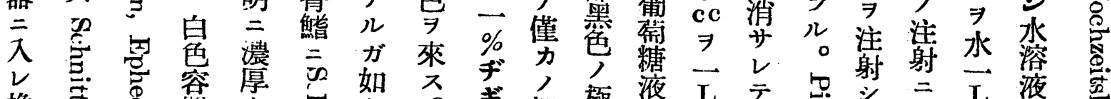

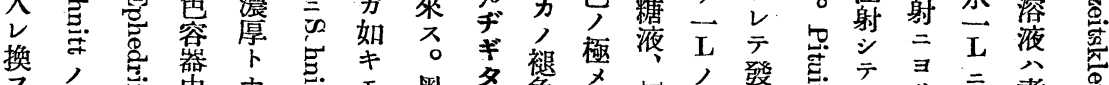
公 兩志

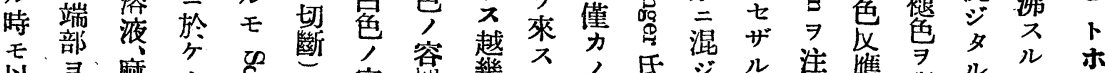

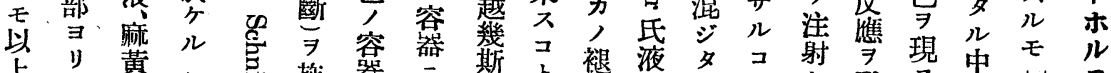

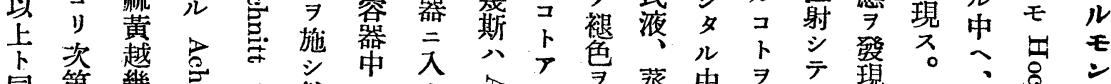
同第幾 㤩 $\exists$ 然

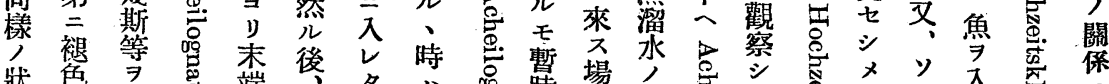
牀色 $\exists$ 注 端柊

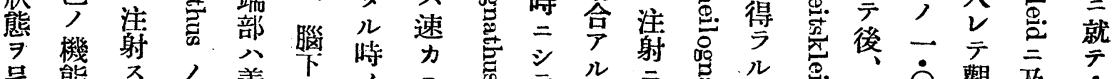

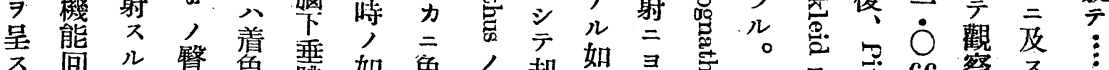

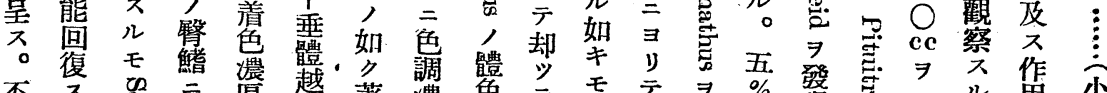
丕

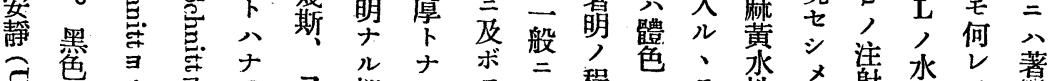

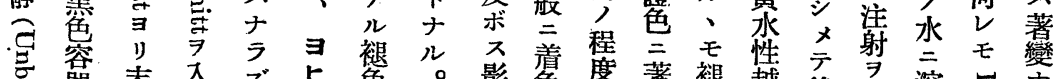
器 端 $レ$ ス

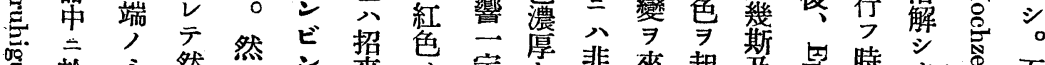

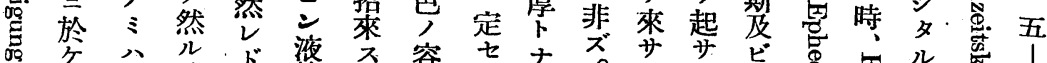

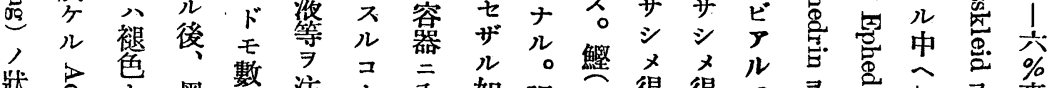

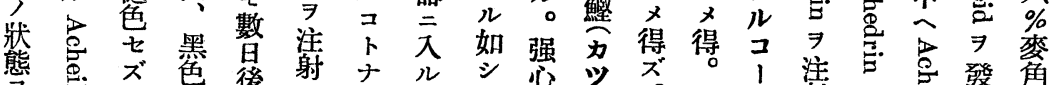

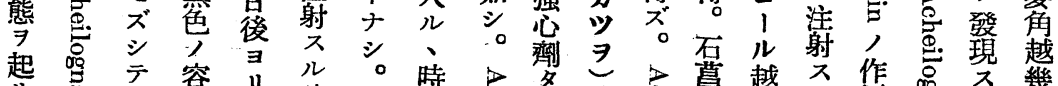

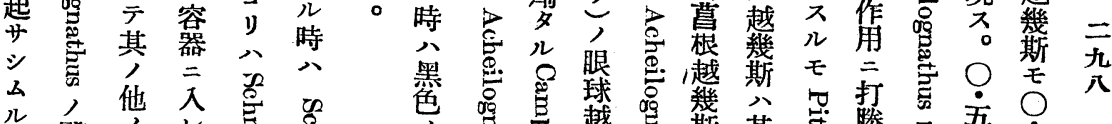

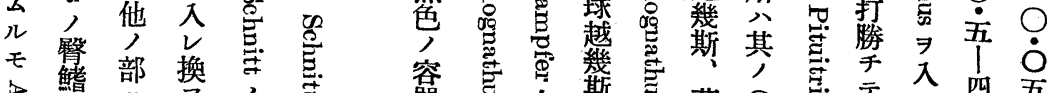

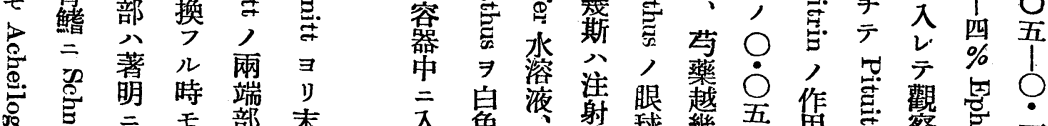

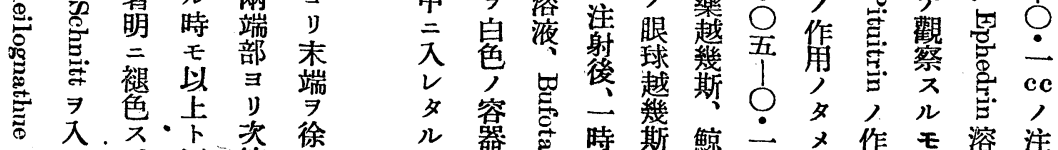

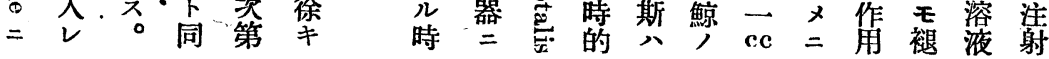




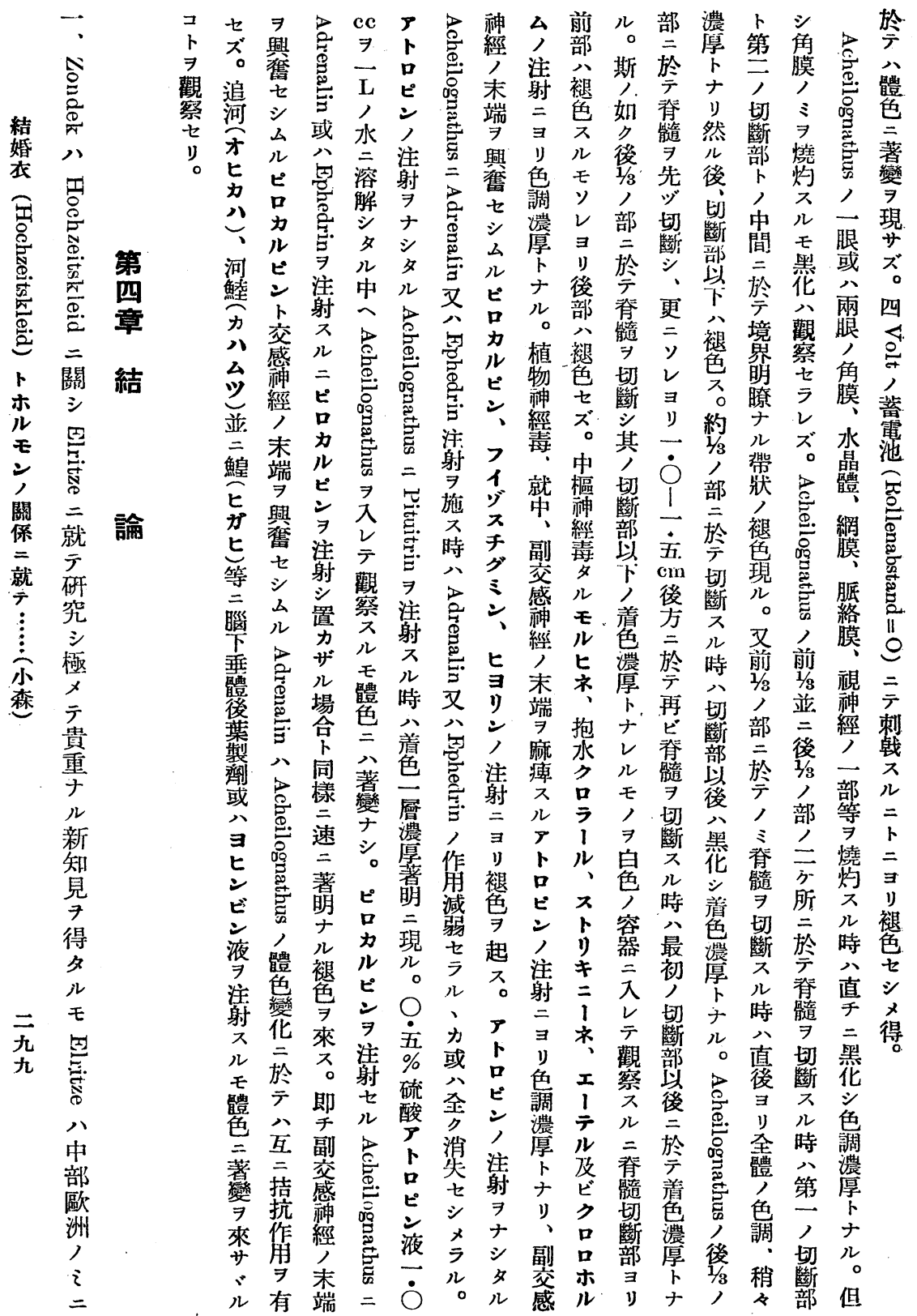




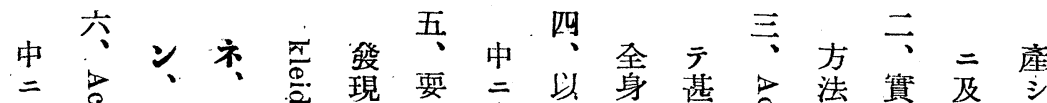

入

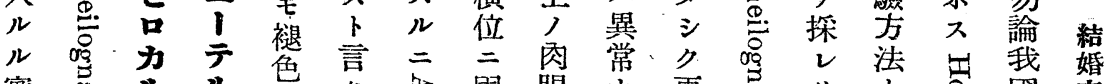

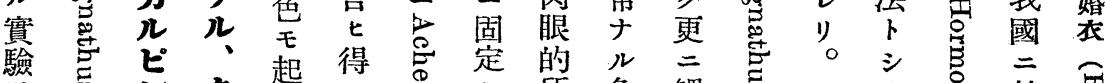

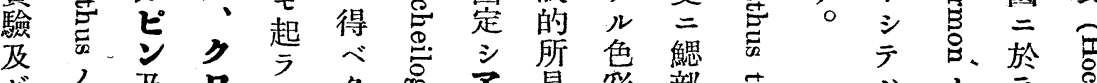

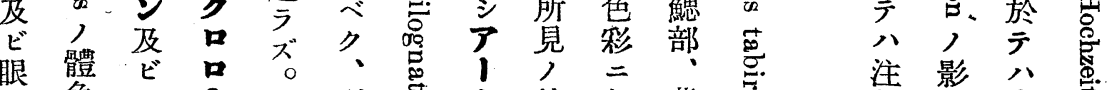

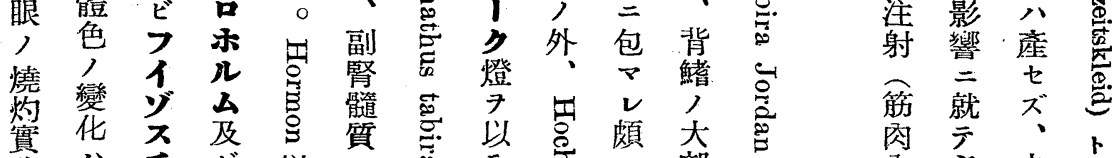

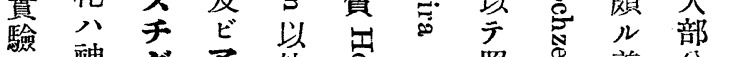

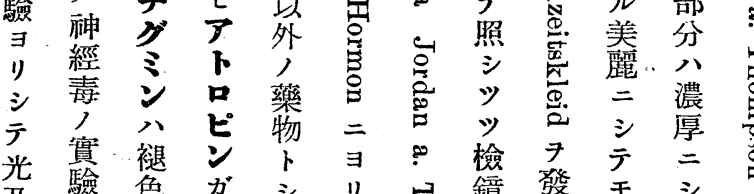

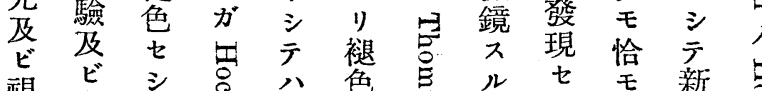

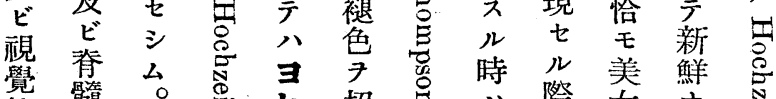

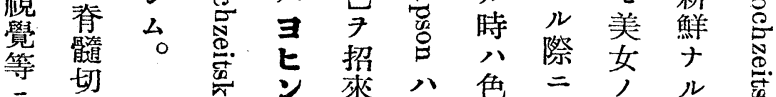

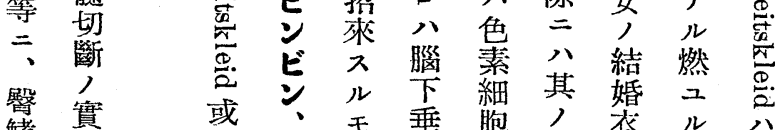

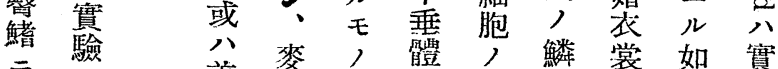

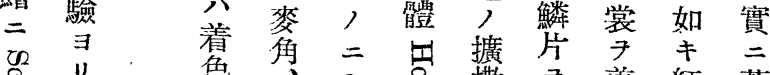

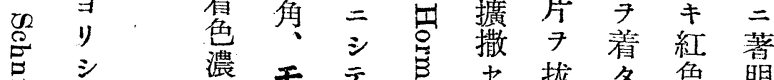

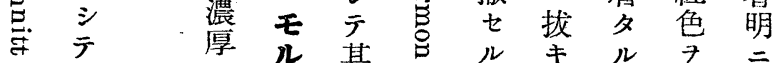

尹. 神.

入經 現齐他射 7 感

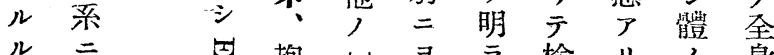

貫: 包抱思

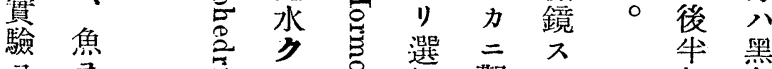

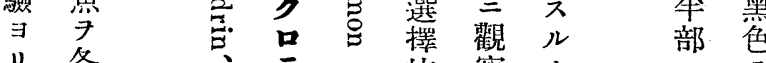

り各、 二 的察力分

神種麻了永二漁稍增

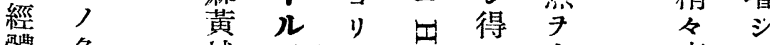

體色、越、テテ岕今生毒背

棭名 有 斯

節 ス

、管

又 器

斯 $\begin{aligned} & \boldsymbol{N} \\ & \mathbf{J}\end{aligned}$

ル帶 各

マ ビ 鱰

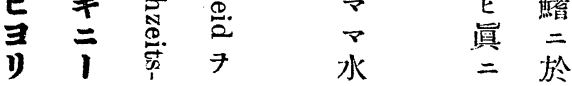

肉示・

內多之柰

$=$ 声代光

$\exists ノ ル 2$

場種采關

合多㷛

亚ルノ就

藥宫

子 遗 尔

定总皆

濃吕 七

度总”。

混获

芕宊

多高余

水 越

中 智

魚总教

翟总曖

䚇 学

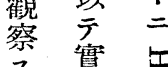

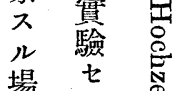

場 七 $\frac{\mathbb{N}}{\mathbb{E}}$

二 


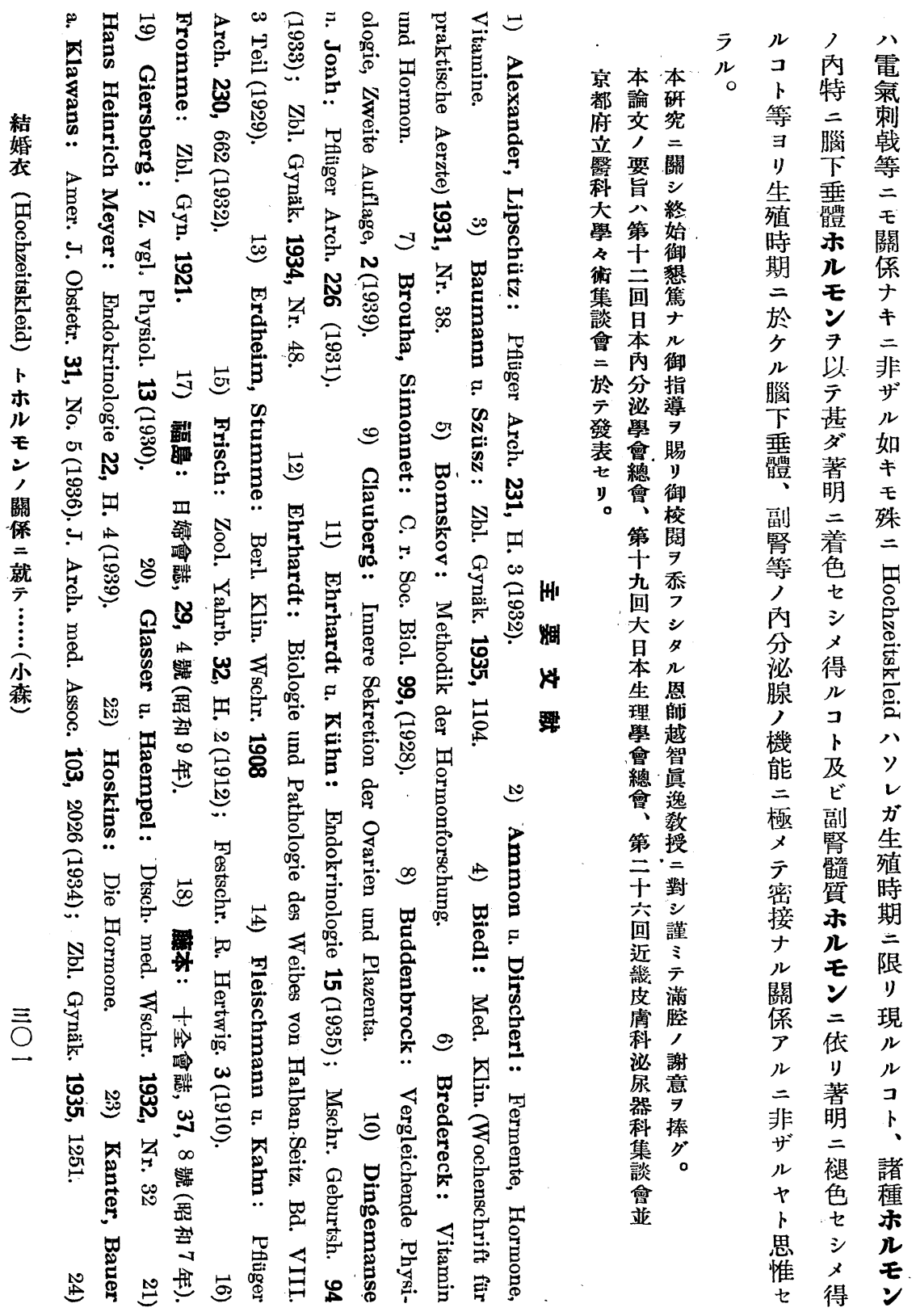




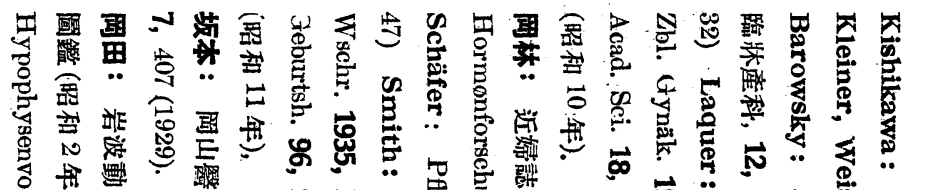

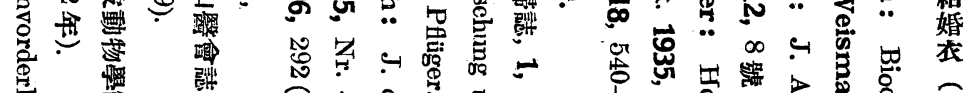

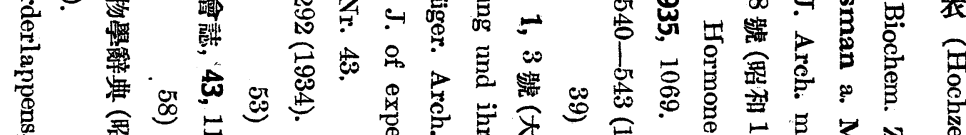

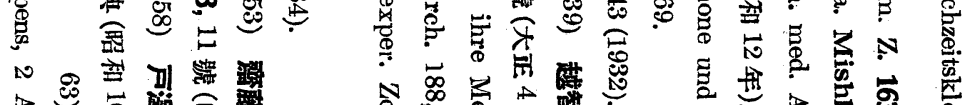

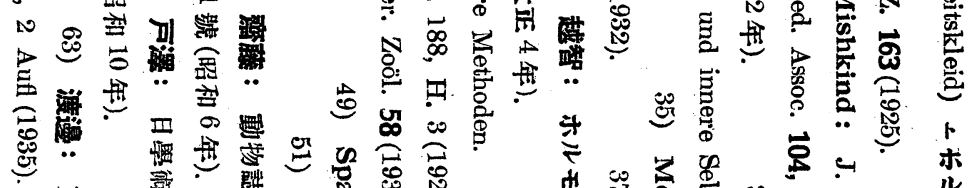

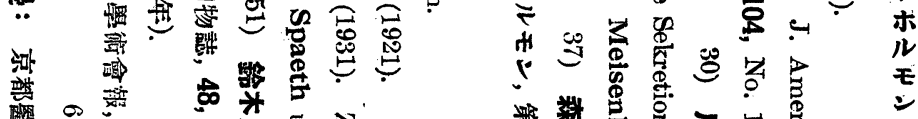

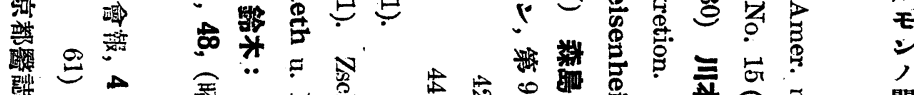

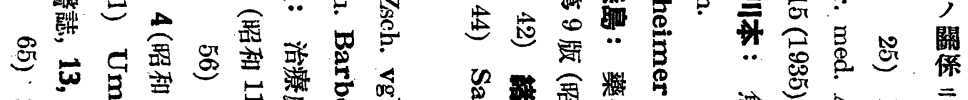

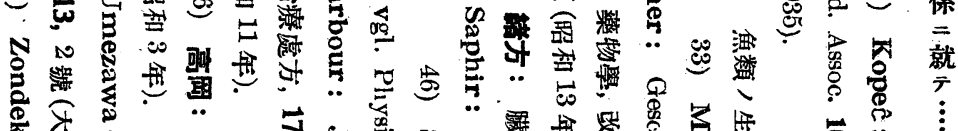

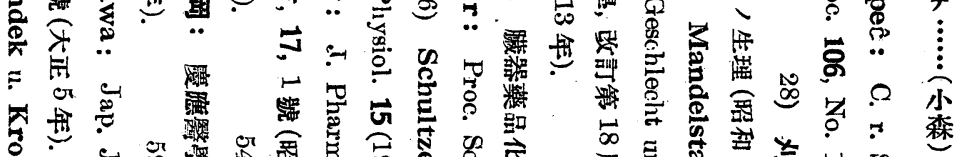

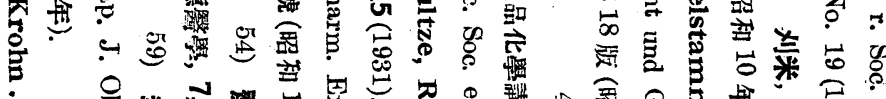

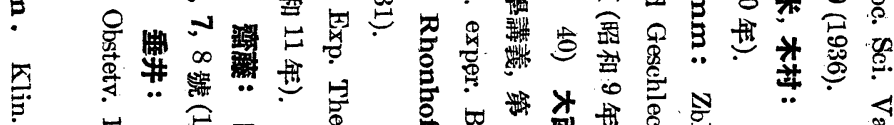

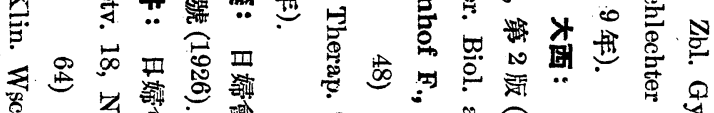

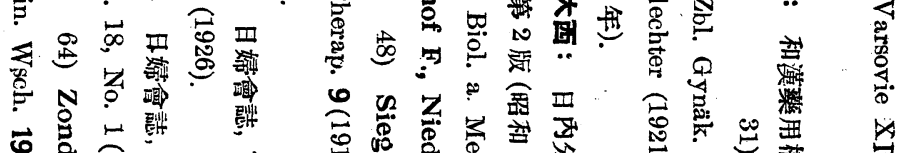

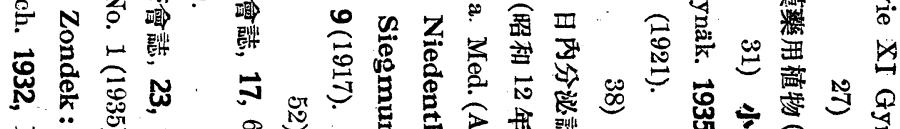
若

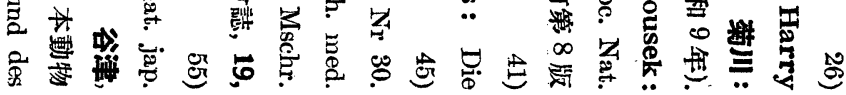


skopisch Leukocyten, hyaline- und granulierte- Zylinder nachweisbar. Stuhlgang bisweilen diarrhoisch geneigt. Sonst 2 malige Blutkultur, Gallenkultur, Widalsche Reaktion und Wassermannsche Reaktion negativ.

Am 23. Feb. 1. Uhr Vormittags gestorben. (Autoreferat)

\title{
Beziehungen zwischen den Hormonenund dem Hochzeitskleid.
}

\author{
Von \\ Shigeru Komori.
}

(Aus dem Physiologischen Institut der Medizinischen Akademie zu Kioto.) (Vorstand: Prof. Dr. Shin-itsu Ochi.)

1. Ich unternahm eine experimentelle Untersuchung über die Beziehungen zwischen den Hormone und dem Hochzeitskleid des Acheilognathus tabira Jordan a. Thompson.

2. Als Untersuchungsmethode wählte ich die folgenden zwei Methoden : (1) Injektion (intramuskulär), (2) Beobachtung des Acheilognathus in Wasser (1 Liter), dem ein Mittel in einen bestimmten Konzentration beigemischt ist.

3. Das Hochzeitsklaid bei dem Acheilognathus tabira Jordan a. Thompson ( $\hat{o}$ ) ist sehr deutlich gekennzeichnet; mann bemerkt Expansion der Erythrophoren, d. h. leuchtende frische purpurrote Färbung an den Kiemen, der Rücken- und Afterflosse sowie Expansion der Melanophoren, d. h. tiefere Schwarzfärbung am ganzen Körper, besonders am Rücken- und Kopfteil.

4. Durch Injektion des Hypophysenhormon (Vorderlappenhormon und Hinterlappenhormon) lässt sich ein deutlich Hochzeitskleid hervortreten erzielen, und durch Injektion des Nebennierenmarkhormon lässt sich deutlich eine Verbleichungsreaktion erzielen, aber sonstige Hormone zeigte jedoch ein negatives Ergebnis.

5. Als Arzneimitteln, bei Yohimisin, Morphin, Chloratum 
hydratum, Strychnin, Aether, Chloroform, Atropin und Secale cornutum tritt Hochzeitskleid oder dicke Färbung auf und bei Ephedrin, Ephedra sinica-Extrakt, Cholin, Pilocarpin und Physostigmin lässt sich eine Verbleichungsreaktion erzielen.

6. Es besteht vielleicht eine sehr enge Beziehung zwischen dem Farbwechsel von Acheilognathus tabira Jordan a. Thompson und den Inneresekretionsdoüsen, besonders wie Hypophyse oder Nebenniere ausser Nervensysthem, Licht, Gesichtssinn, neurohumoraler Reizübertragung und Elektrischem Reiz usw..

(Autoreferat)

\section{Experimentelle Studien über den Einfluss des thyreotropen Hormons der Hypophyse auf den Zuckerstoffwechsel. I. Mitteilung.}

Über den Einfluss des thyreotropen Hormons auf den Blutzucker und zugleich über-die Wechselbeziehung zwischen thyreotropem Hormon und verschiedenen Nervengiften. Von Dr. W. Nakahara

(Aus der I. Med. Klinik der Kaiserl. Universität zu Kyoto in Japan. Direktor.: Prof. Dr. K. Tsuji und Prof. Dr. K. Inoue)

Der Verfasser untersuchte den Einfluss des thyreotropen Hormons auf den Blutzucker des Kaninchens. Das thyreotrope Hormon wurde aus Rinderhypophyse nach dem Loeserschen Verfahren hergestellt. Dieses Hormon wurde dem Kaninchen in kleiner oder grosser Menge ( 5 bis $30 \mathrm{mg}$ Hormonpulver-entsprechend 0,35 bis $2,1 \mathrm{~g}$ getrocknetem Hypophysenvorderlappenpulver) einmal oder 5 Tage hintereinander täglioh einmal injiziert. Bei der einmaligen Injektion wurde der Verlauf der Blutzuckerkurve nach der Injektion verfolgt. Wei- 